\title{
De los barrios chinos en Latinoamérica y el Caribe ${ }^{1}$ Chinese Neighborhoods in Latin America and the Caribbean
}

Fecha recepción: octubre 2020 / fecha aceptación: enero 2021

Yrmina Gloria Eng Menéndez²

DOI: https://doi.org/10.51188/rrts.num24.468

\begin{abstract}
Resumen
El texto entrega aspectos introductorios sobre las migraciones chinas y la inserción del componente chino en las sociedades de la región. Reflexiona sobre los Chinatowns o barrios chinos históricos y tradicionales y las nuevas propuestas como atractivos comerciales y turísticos. El trabajo se centra en mostrar las particularidades de los barrios chinos en América Latina y El Caribe. Asimismo, analiza los programas de reanimación de barrios chinos en la región -México DF, La Habana, Santo Domingo, Buenos Aires-, la creación de nuevos proyectos -San José, Costa Rica- y la significación de éstos en las relaciones bilaterales entre China y los países en que se encuentran.
\end{abstract}

Palabras clave: comunidades chinas; barrios chinos o Chinatowns; proyectos de reanimación.

\begin{abstract}
This article provides introductory aspects about Chinese migrations and the insertion of the Chinese component in the societies of the region. It reflects on the Chinatowns or historic and traditional Chinese neighborhoods and the new proposals as commercial and tourist attractions. The work focuses on showing the peculiarities of Chinatowns in Latin America and the Caribbean. Likewise, it analyzes the development programs of Chinatowns in the region -Mexico DF, Havana, Santo Domingo, Buenos Aires-, the creation of new projects -San José, Costa Rica- and their significance in bilateral relations with China.
\end{abstract}

Keywords: Chinese communities; Chinatowns; development projects.

\footnotetext{
1 Versión actualizada y modificada según las indicaciones de los evaluadores externos de este número especial, del ensayo de la propia autora Barrios chinos de América Latina y El Caribe (Eng, 2015).

2 Licenciada en Sociología y Máster en Antropología, Doctoranda en Ciencias Sociológicas. Profesora Auxiliar en la Facultad de Artes y Letras de la Universidad de La Habana, Investigadora Agregada por el Instituto Cubano de Antropología. Dirección postal: Luz Caballero 202, Apto. 2, Santos Suárez, 10 de Octubre, La Habana, Cuba. Email: yrmina@fayl.uh.cu,yrmina0605@gmail.com
} 


\section{Origen de los barrios chinos o Chinatowns}

Los chinos comienzan a aparecer en América en tiempos de la Nao de Manila, que por siglos constituyó una forma de comunicación y comercio entre Occidente y Oriente. Pero no fue hasta mediados del XIX que se inician las grandes oleadas periódicas de culíes primero ${ }^{3}$ y después, a través del proceso llamado en cadena o "one brings another" (López, 2004, p.93), que ha continuado la migración china por el mundo. El proceso de reforma y apertura en China después de 1978 incrementó y diversificó la emigración significativamente, dirigiéndose hacia unos 150 países, procedentes de las más diversas regiones de China. En las últimas décadas han cambiado los patrones migratorios y el comportamiento de la diáspora, incrementándose el flujo hacia nuevos destinos de América Latina, África y Europa, donde las redes de relaciones intracomunitarias se extienden y fortalecen (Bogado, 2011).

La migración masiva fue un recurso socioeconómico alentado por las necesidades de mano de obra del sistema capitalista de producción en expansión hacia los territorios coloniales y la crisis del sistema dinástico en China. En ese sentido insertó a China, a través de sus migrantes, en la escena de un primer importante proceso de mundialización. En general, los primeros grupos migrantes -siglo XIX y la gran mayoría del XX- eran chinos pobres, procedentes de las clases más bajas de una sociedad rural, base de la trata de culíes, que luego de liberados de los compromisos por los que fueron empujados al largo viaje (Eng, 2003), encontraron en las grandes ciudades de los países de destino, un sitio donde enclavarse. Con esa mitificada laboriosidad, paciencia, austeridad, persistencia y resistencia justamente atribuidas a los chinos, unidas a la habilidad mostrada para los negocios, estos inmigrantes se expandieron y anclaron en comunidades creadas por ellos mismos, a través de las redes tradicionales chinas de familia y parentesco, los conocidos clanes o tong. Llegaban materialmente pobres, pero culturalmente ricos, y estos recursos socioculturales les valieron para enfrentar el nuevo medio y los procesos de discriminación, racismo y xenofobia de que fueron objeto (Hu-DeHart, 1982; 2009). Entre las formas de asentamiento nacidas de dichas migraciones étnicas se encuentran los barrios chinos o Chinatowns, reflejando la tendencia a la localización urbana de las poblaciones chinas (Pan, 1999; Rodríguez, 2001).

En los barrios chinos, como emporios del Este (Pan, 1990), se podían encontrar todo tipo de actividades y productos típicos chinos, costumbres y hábitos -bien o mal vistos como el juego y la prostitución, los fumaderos de opio, o la quema de inciensos a los ancestros, entre otros-. Y aunque todos los Chinatowns pudieran parecerse, no son exactamente iguales. Tampoco hay un barrio chino tipo. Han surgido barrios chinos en áreas rurales, en zonas suburbanas; algunos completamente modernos, cuyos edificios han sido construidos por y para los chinos en tiempos modernos, en contraste con los primeros radicados en el downtown o partes viejas y cosmopolitas de grandes ciudades de Asia, América y

3 Latinoamérica tuvo un importante peso en el tráfico de culíes, particularmente el Caribe, que asimiló el 18\% y de ellos solamente Cuba el 15\% (Eng, 2013a); llegando a la isla británica de Trinidad en 1806 (Checa-Artasu, 2013). 
Europa. Alguno como el de Victoria ${ }^{4}$, que se adelantó a la creación de la ciudad fue asentamiento pionero de chinos en Canadá, objeto de un programa de restauración en los años 1970 que le añadió valor patrimonial (Lai y Madoff, 1997). El Barrio Chino de Bangkok tiene como trasfondo de su historia un gran bazar y es tan viejo como Bangkok misma. Distinguido por sus joyerías y farmacias, puede considerarse uno de los más completos. El de Londres es relativamente nuevo, de los 60 del siglo $X X$, coincidiendo con las grandes oleadas migratorias de hongkoneses hacia Gran Bretaña entre 1962 y 1966 (Pan, 1990). El glamoroso Chinatown de San Francisco5, con su mítica existencia desde el siglo XIX, es el más famoso de los barrios étnicos en Norteamérica al que Genthe le Ilamó "Canton of the West" (Genthe y Tchen, 1984, p.10). El más antiguo de New York -el Manhattan Chinatown- data de 1844 y tiene su origen en una tienda. Los chinos iban a Manhattan como parte de las oleadas de inmigrantes de todos los orígenes: "All the world is in New York, and the Chinese, who are in all the world, are in New York in force" (Pan, 1990, p.304). Algunas de las grandes ciudades abrigan dos o más Barrios Chinos, Chinatowns o Quarter Chinoise como Nueva York, Los Angeles, Toronto o París, también Lima.

\section{Caracterizando los barrios chinos}

Los barrios chinos muestran una etno-cultura de resistencia, marcada por la distancia entre la cultura de la sociedad anfitriona y la de la comunidad insertada o inmigrante, desarrollando una trama socio-urbana que permitía distinguirlo sin señalizaciones para la delimitación territorial, ni la diferenciación de recursos inmobiliarios y/o mobiliarios del entorno urbano en que estaban insertos como un enclave étnico (Hu-DeHart, 2012). Los chinos sufrían un fuerte impacto sociocultural a su llegada, afectados por la imposibilidad de comunicación personal, con total desconocimiento del funcionamiento social, en un medio discriminador construido por la ideología racista para justificar la explotación de los inmigrantes. Por lo que una función de estos barrios fue servir de espacios de adaptación, "utilizados por los inmigrantes como trampolín para la aculturación y la asimilación en la sociedad canadiense" (Lai y Madoff, 1997, p.53). Son una forma de asentamiento que se caracteriza por la segregación etno-espacial (Eng, 2013b) en aquellos sitios donde la presencia de estos asiáticos tuvo "un volumen y una dinámica intensa" (Alba, 2009, p.83).

Por lo general se localiza en zonas urbanas céntricas y en el área tradicional o antigua de las ciudades populosas ${ }^{6}$. Los barrios chinos históricos funcionalmente son integrales y autosuficientes, de manera que la función residencial se complementa e integra con las demás funciones básicas, cotidianas (laboral, educativa, diversidad

4 La autora realizó un recorrido guiado por el Chinatown de Victoria en diciembre de 1998 en compañía de David Chuenyan Lai, miembro de la comunidad china y del equipo que encabezó el proyecto de reanimación arquitectónica y urbanística de la zona.

5 La autora realizó varias visitas en marzo-abril 1998, reuniéndose con directivos de las asociaciones chinas de San Francisco y académicos estudiosos de la diáspora en EEUU.

6 De acuerdo a la información que ha logrado obtener la autora, ya sea por vía personal experiencial o en la consulta de documentos -libros, artículos especializados y periodísticos-, ésta ha sido una regularidad: los barrios chinos de Lima, Perú; de Victoria, Vancouver y Toronto, los más antiguos de Canadá; los muy famosos de Manhattan y San Francisco, Estados Unidos; los de Ciudad México, Ciudad de Panamá y otros muchos del continente americano. 
de servicios, actividades culturales, recreativas) y de todo tipo requeridas para la vida social, material y espiritual de la población local. Incluye gran variedad de actividades productivas y de servicios, con fines de recreación, información, instrucción, entre muchas, que satisfacen la diversidad de necesidades materiales y espirituales de su población autóctona china: escuelas, consultorios médicos, jurídicos, periódicos, revistas, cines y teatros chinos, barberías, reparadoras, las lavanderías chinas -conocidas en Cuba por "trenes de lavado""-, tiendas, instituciones asociativas de diferentes perfiles (social, cultural, político, económico, profesional, deportivo, etc.), a tono con la estructura de las comunidades de inmigrantes. También se satisfacen las demandas de una población flotante que viene en busca de los atractivos comerciales y culturales que ofrecen. Al decir de Padura "una pequeña ciudad asiática en miniatura" (Padura, 2002, p.17), con todo lo que se requiere en una comunidad independiente, pero completamente conectada con un entorno citadino. Es importante que quede claro que existen actividades sociales y económicas, servicios y productos, propios para los chinos y otros para los no chinos que conforman la población no china residente y flotante. Mientras pululan restaurantes, donde la comida china que se ofrece está adaptada comercialmente para ser aceptada por el gusto occidental, otros son los establecimientos de productos dirigidos al paisano, consumidor chino, con las indicaciones en idioma chino y un menú adecuado a sus gustos domésticos (Eng, 2013a).

Estas manifestaciones de proyección dual como caras del barrio son expresión de la "frontera a literal entre ambas culturas" (Alba, 2009, p.83). Son una muestra de los recursos culturales puestos en función de la subsistencia sociocultural como individuo y grupo "propiciando una construcción identitaria resguardada del 'Otro'" (Alba, 2009, p.83).

Tenían todo lo que se requería en una comunidad independiente, pero completamente conectada con su entorno local, nacional e internacional, a través de las redes de relaciones intracomunitarias y entre comunidades que son un capital importante, característico y sobresaliente en la dinámica de las comunidades chinas en el mundo (Bogado, 2011). Las asociaciones chinas son instrumentadas transculturadamente para reproducirse y protegerse en el nuevo contexto en su quehacer político, cultural y social y devinieron en estructuras básicas de los chinos en la emigración. Verdaderas organizaciones con redes internacionales que tienen sus raíces en China, donde las sociedades secretas fueron los antecedentes directos $y$, junto a las estructuras e instituciones tradicionales de las aldeas campesinas por apellidos y la vida en familia extendida, fueron los fondos culturales para construir un nuevo modo de vida donde perviven elementos tradicionales de la vida anterior, innovados de la manera en que los nuevos escenarios, en las sociedades receptoras, obligaron a reconstruir.

En este proceso las relaciones interculturales que tienen lugar son de una enorme y compleja riqueza. Se generan nuevos valores, resultado del intercambio entre las comunidades receptoras e insertadas, que se modifican y enriquecen

\footnotetext{
7 Según testimonios de los entrevistados, la causa del nombre de tren de lavado se debe a un tipo de lavandería que usaba una máquina de lavar de las primeras que existieron cuyo sonido era semejante al que hace el tren: "chach, chach, chach".
} 
mutuamente, dejando de ser lo que eran antes de la interacción. Es la manifestación del proceso de transculturación ${ }^{8}$ en el que lo que resulta no es ni lo uno ni lo otro, aunque procede de ambos y porta rasgos que caracterizan a ambas sociedades interconectadas a través de la diáspora.

Con los barrios chinos se muestra una de las formas de reacción más perfeccionadas que los procesos de marginalización han creado, en este caso, de la mano de la automarginación, en forma de autoprotección y defensa del grupo etnosocial $^{9}$. La estructura interna reproduce diferencias y mecanismos sociales que en la China de la época regían y que son reajustados al nuevo medio cultural, económico y social. Estos barrios son expresión de ese proceso de adaptaciones, a veces violentas, racializantes, encubridoras de las causas que participaron en la forma que adopta el resultado final, pero siempre novedosas, aportando y enriqueciendo valores locales. En el caso de los chinos no podía ser de otra forma. Cultura milenaria arraigada fuertemente en cada individuo -portador de una identidad consolidada a través de un larguísimo proceso de natura social-, fuente de recursos culturales a los que se recurre en condiciones de crisis de la existencia, cuando no se posee más que lo intrínseco al ser humano. Valores reconstruidos en el nuevo contexto.

En la medida que prosperaban sus negocios, fueron invirtiendo en caracterizar la localidad habitada con elementos arquitectónicos decorativos tradicionales chinos. Entre los más comunes están los arcos o puertas de entrada, las pagodas, los aleros a semejanza de los techos chinos y los letreros en ideogramas usando distintos estilos de la caligrafía china, que aportan una fuerza identitaria de gran impacto cultural, por el elaborado y profundo grado de simbolismo.

El barrio chino da centralidad a lo chino. Funcionan como centros de reunión y como espacios de transmisión de los símbolos culturales a la propia comunidad china y a la sociedad mayoritaria, que también lo frecuenta e interactúa con los residentes chinos, dinámica que ha contribuido a la interacción entre culturas e individuos (Bogado, 2011).

Con el tiempo los barrios chinos se han convertido en atractivos turísticos que manifiestan la cultura china a través de la comunidad portadora, trasmitiendo una poderosa imagen, tejida en el entramado resultante de la conjugación de intereses y recursos puestos en juego para la sobrevivencia y resistencia cultural en la emigración. Uno de los icónicos ejemplos es el espectáculo de las fiestas tradicionales chinas por el Año Nuevo Lunar. Los Chinatowns de San Francisco y Manhattan contaron tempranamente con afluencia turística y opciones de recorridos para disfrutar de la experiencia cultural que ofrecían y son hasta hoy

8 Como muchos manejan, transculturación es un concepto desarrollado por Fernando Ortiz en El Contrapunteo Cubano del Tabaco y el Azúcar (Ortiz, 1940), una de sus obras mayores y constituye uno de los aportes más importantes del sabio cubano, también conocido como tercer descubridor de Cuba. Se refiere al proceso que tiene lugar entre valores de diferentes culturas debido a la interrelación entre sus portadores, resultado del cual se transforman dichos valores, surgiendo formas y elementos nuevos y distintos de los que le dieron origen.

9 Un tema negro sobre los inmigrantes chinos frecuentemente mitificado en la prensa, pero poco explicitado, que merecería mayor tratamiento desde lo académico. 
atractivos turísticos indiscutibles de las dos ciudades, bien posicionados en las guías para visitantes.

Los que proliferaron en las décadas del 70 y del 80 del pasado siglo -aunque no solo, sí fundamentalmente en América del Norte- fueron recreaciones de los primeros, motivadas por el boom comercial de la comida china y del turismo. Diferenciables de los Chinatowns tradicionales, estos nuevos desarrollos son callecitas, bulevares o centros comerciales caracterizados con decoración típica china, repletos de establecimientos que ofrecen productos y servicios tradicionales chinos: tiendas, farmacias, restaurantes, tratamientos de medicina tradicional y masajes, etc. En América Latina y el Caribe este tipo de propuesta fue apareciendo un poco más tarde, de la mano de la emergencia de China como nuevo gigante en la escena económica y política internacional. En algunos casos y respondiendo también a dinámicas locales, para incidir en el fortalecimiento de las relaciones bilaterales. Tal es el caso de la reanimación de una calle peatonal en el histórico Barrio Chino de Lima en los 1970, o el de Dolores en México, D. F. y uno de los más recientes, el de San José, Costa Rica, en el 2012. Otros, como los distintos intentos en el barrio chino habanero, a partir de finales de la década 1980, proyectos de reanimación urbanística y comercial, que en los años 90 contó con la participación comprometida de la comunidad china. Todos instrumentando el papel de los chinos locales y sus comunidades, como actores no estatales e informales en las estrategias de las relaciones bilaterales entre la República Popular China y los países latinoamericanos, para cultivar las relaciones informales y el acercamiento desde las relaciones de confianza y amistad (Gómez, 2013; Hearn, 2012).

\section{Barrios chinos en América Latina y El Caribe. Proceso de revitalización y reconstrucción de la identidad de los barrios chinos de la región y los nuevos proyectos ejecutados}

Los barrios chinos históricos de la región son los de La Habana y Lima, que comparten época y condiciones similares en sus procesos de surgimiento y desarrollo. Se pueblan con los culíes que terminaban sus contratos de trabajo y comenzaban a emigrar hacia las ciudades, estableciendo pequeños comercios de mercaderías, alimentos y comidas.

Los orígenes del Barrio Chino de Zanja se encuentran en 1858 cuando se abre "una pequeña casa de comida china en La Habana" (Chufat, 1927, p. 17), rodeando la Zanja Real, con siembras de hortalizas y perfilando el lugar para el asentamiento de viviendas, comercios y demás actividades de los chinos en ciudad. Una zona de La Habana extramuros rodeada de fábricas de tabaco donde los culíes y liberados fueron importante mano de obra. Al decir de Padura (2002, p.28) "iba adquiriendo su definitivo espíritu de una ciudad asiática en miniatura". Se dice que desde los años 1850 se podía ver la concentración de inmigrantes chinos en los alrededores de la calle Capón, donde "el ex culí residía masivamente en Lima desde los años 1870, (...) e hizo que la calle Capón fuese reconocida como suya” (Rodríguez, 2001, p.220-221). Ambos barrios -el de Capón en Lima y el de Zanja en La Habana-, colindantes con los centros históricos de las dos importantes ciudades capitales, también se radicaron cerca de sus grandes mercados de la época -la Plaza del Vapor 
en La Habana y el Mercado Central de Lima-, en zonas urbanas con arquitectura del $\mathrm{XIX}$, lo que refuerza el paralelismo y la similitud de ambos procesos de desarrollo ${ }^{10}$.

En los inicios del siglo $X X$ aparecieron en ambos barrios chinos empresas importadoras - de arroz, té, sedas, porcelana, alfombras, losa y otras mercancías que traían de la China- y pululaban asociaciones y periódicos chinos, junto a todo tipo de servicios y comercios. A esas partes viejas y céntricas de las dos ciudades acudían intelectuales y artistas de la época, sensibles para detectar ambientes auténticos donde practicar su bohemia, disfrutando de expresiones culturales emergentes y resultado del acriollamiento. Los chifas representan el iceberg de la cultura tusán ${ }^{17}$. Son los restaurantes chino-peruanos, particularmente populares y que forman parte de la culinaria peruana producto de la fusión de las cocinas china y criolla. El propio término chifa es resultado del proceso lingüístico de apropiación cultural, a partir de la transliteración de la expresión china chi fan! que significa en chino cantonés comer arroz o comer comida, equivalente al llamado A comer! en español y que a la vez se usa de saludo en la lengua cantonesa (Rodríguez, 2004). O el teatro chino -del que Carpentier (2002) escribiera una crónica publicada en el año 1940-, que refleja la pujanza de esta expresión artística en el barrio chino habanero.

Tanto en La Habana como en Lima y en otras ciudades de los dos países, los sectores chinos crecieron, repletos de pequeños negocios (restaurantes, lavanderías, tiendas). Originaron un remarcable asociacionismo cuyas entidades se concentraron en estos barrios chinos, muchas de las cuales aún activas, constituyen evidencia histórica de la vida social de momentos originarios.

El Barrio Chino de La Habana prosperó, y ya en los años 30 del XX se extendía más allá de 40 manzanas con un estimado de población de 30 a 40 mil residentes. Por lo que su esplendor se sitúa en el período comprendido entre 1930 y 1950; su etapa de decadencia a partir de los años 60, se acentúa en los 70, tocando fondo al final de los 80, proceso estrechamente ligado a las transformaciones del sistema social cubano después del triunfo de la Revolución de 1959 (Eng, 2007). Hubo intentos de auto-recuperación por parte de la propia comunidad china en los 80 y 90, con proyectos de rescate de tradiciones artísticas y de reanimación del barrio chino habanero, gracias a los cuales aún se puede considerar una presencia china en Cuba con un grado de vigencia de tradiciones y festividades, restaurantes y prácticas de artes marciales y ejercicios tradicionales chinos.

Actualmente la vida social de la comunidad china en Cuba se realiza espacialmente en el Barrio Chino, donde se encuentran activas trece asociaciones, encabezadas por el Casino Chung Wah, hace pocos años rediseñada como Federación de Sociedades Chinas de Cuba. La población de origen chino en Cuba está integrada por una centena escasa de chinos inmigrantes, muy ancianos

10 La autora ha realizado trabajo de campo en los barrios y comunidades chinas de Lima (diciembre 2016 y agosto 2018) y La Habana a partir de 1993.

11 Tusán es el término peruano con el que se identifica a los chinos peruanos. Significan la nueva identidad y cultura resultado del mestizaje social y biológico que aportan los chinos al Perú. La cultura tusán está ampliamente extendida en el país como un componente de la cultura peruana y de la que participan activamente los peruanos sin origen chino 
ya, cubanizados desde todos los puntos de vista. La descendencia cubana es numerosa y sobre la que no existe un registro totalizador -hay estimados de unos 20 mil nada confiables-, cuyo lado chino ha tenido muy limitadas posibilidades de influencia en su educación y cultura. A pesar de que en el barrio apenas residen personas de ancestros chinos, "desde la memoria, entendida como un recurso cultural para construir identidad, pero también como un dispositivo de poder" (Cinco, 2017, p.165), el Grupo Promotor del Barrio Chino, creado y encabezado por descendientes, encarnó el ADN cultural asiático enraizado por más de cien años en la isla y desarrolló el Proyecto Integral de Reanimación del Barrio Chino de La Habana. ${ }^{12}$ Ese proyecto sombrilla logró en los años 1990 transformar el deterioro y la pérdida y reactivar un conjunto de instalaciones comerciales del callejón de Cuchillo de Zanja, corazón del barrio chino, que conforman la principal actividad económica y comercial del mismo. Junto a la celebración de las festividades tradicionales y patrióticas del pueblo chino y la creación de eventos para festejar los aniversarios de la presencia china en Cuba, las asociaciones y el barrio renaciente volvieron a hacerse visibles, logrando detener el inminente proceso de desaparición en que se vio inmerso a finales de los años 1980 y que de nuevo amenaza entrado el siglo $X X I$. Este renacimiento en el contexto de la dura crisis estructural cubana de los 90, fue acompañado de incursiones exitosas en la gestión empresarial vinculada a las tradicionales actividades comerciales del barrio chino que se habían perdido. Resultó un marcado aporte en la incipiente actividad económica privada en Cuba que llamó la atención de la prensa y autoridades gubernamentales y académicas de muchas partes (Hearn, 2012 y 2016; López, 2010 y 2013; López-Calvo, 2007, entre varios).

En el Perú se ha referido que aproximadamente 2 millones y medio de personas tienen ancestro chino, considerando cifras relativas del $8 \%$ y hasta un $10 \%$ de la población peruana según Lausent-Herrera (2011). Lo cierto es que en el andino país la diáspora china es una de las más numerosas en el ultramar chino y la presencia china más notable en Latinoamérica. El antiguo barrio chino de Capón se transforma en la contemporaneidad. Deteriorado al arribar a los años 1970, se convirtió en un abandonado y peligroso sitio de la ciudad. Fue la alcaldía de Lima quien impulsara el proyecto de reanimación urbana por el que en 1997 el arco o portón chino -donada por Taiwan en 1971- fue restaurado junto con ese rincón de la ciudad valorado de entrañable e imprescindible por la prensa ${ }^{13}$. La nueva zona china o barrio chino de Lima en San Borja ${ }^{14}$ refleja el poderío económico y social de la diáspora más reciente y de la vieja comunidad. En la barriada residencial de San Borja los supermercados y grandes restaurantes y demás establecimientos chinos indican la tendencia de una comunidad asiática cuya diáspora se renueva y enriquece sus viejas raíces.

No se puede hablar de chinos en México, sin mencionar a Mexicali como la localidad del país donde lo chino es casi autóctono, porque llegaron con el surgimiento de la ciudad misma (Alba, 2009) procedentes de Estados Unidos,

12 La autora creó y fundó dicho Proyecto de Reanimación como parte de una investigación-acción durante 7 años. Creó, fundó y dirigió por 5 años el Grupo Promotor.

13 Consultar Guía Turística de Lima, 2014 y los testimonios de miembros de la comunidad peruano-china 14 Ver inmigración china en Perú. Wikipedia 
concentrando la mayor población china en el país. Llamado La Chinesca, data de inicios del siglo XX y es el barrio chino más grande en México, donde los cafés de chinos se dispersan por toda la ciudad y se refiere una cifra de 200 restaurantes de comida china ${ }^{15}$.

Mientras que existen evidencias de chinos laborando en cafeterías en Mexicali desde inicios del XX (Cinco, 2014), los chinos del D.F. vinieron en la década de 1920 del norte del país, precisamente de Tijuana y Mexicali, huyendo del movimiento antichino que los barría de esas localidades. Con la apertura del Restaurante Shanghai en 1940, surge el Barrio Chino de la calle Dolores ${ }^{16}$ en la ciudad de México, como espacio comercial del Centro Histórico, colindante con el Palacio de Bellas Artes. Más que un sitio de reproducción cultural para la propia comunidad tenía una lectura de estigmatización y prejuicios sobre el significado de lo chino para la población local (Cinco, 2014). También hubo casinos en donde se reunían para jugar majong y fumar opio, contribuyendo con ello a la imagen negativa que perduró durante décadas. Tiempo después, ante el deterioro del lugar, el entonces Jefe del Gobierno de la capital lanzó un proyecto de Rehabilitación del Barrio Chino de Dolores y a partir del 2006 se ejecutan las acciones constructivas, que transformaron la transitada calle de vehículos en una calle peatonal repleta de comercios de objetos y comidas chinas. Contó con el interés y el quehacer de miembros de la comunidad china en la ciudad, autenticando así el espíritu chino del lugar con fines turísticos, actividad en la que se destaca el arquitecto Alfonso Chiu. Donado por la República Popular China, el Arco Chino fue inaugurado el 16 de febrero de 2008 por el embajador chino y el máximo representante del gobierno en la ciudad de México.

Panamá cuenta con población china desde 1854 cuando llegan los culíes al Istmo para la construcción del ferrocarril. Su viejo barrio chino del distrito Capital de Panamá es una zona del centro antiguo cercana al mercado público central, conocido como Salsipuesdes. Ahora ya muy deteriorado aquel lugar, y acorde con la gran población china actualmente radicada en Panamá, se observa el desarrollo de otra zona comercial china en El Dorado, con condiciones de urbanización muy superiores (Tam, 2006), que muestra la fuerza de la diáspora en Centroamérica. ${ }^{17}$

Los primeros chinos a República Dominicana venían huyendo de las plantaciones azucareras de Cuba y de Jamaica, y después siguieron llegando directamente de Guangdong a través de la cadena migratoria (Eng, 2011, 2015). En Santo Domingo vienen concentrándose por más de un siglo en los alrededores de la Avenida Duarte, en una de las zonas comerciales de la ciudad, cuyo auge se inicia con la actividad comercial de mayor nivel que promovieron los inmigrantes chinos que después de la Segunda Guerra Mundial fracasaban en su intento de alcanzar los EEUU (López, 2010). Sigue diversificándose con los procedentes de Hong Kong y Taiwan, que en los 80 y 90 del siglo XX salían por el temor a los cambios a finales del siglo con el traspaso de esos territorios a la República Popular. El movimiento para la oficialización de la zona como Barrio Chino, completando la reanimación

15 Ver Inmigración china en México. Historia. Wikipedia

16 La autora ha visitado el lugar (2005, 2012, 2013, 2014, 2016, 2018) y se ha entrevistado con miembros destacados de la vieja comunidad que participaron en el proyecto de los años 80, como es Alfonso Chiu.

17 La autora recorrió las dos zonas en agosto de 2014. 
urbanística del lugar, culminó en el 2006 con la ceremonia de inauguración del arco de entrada o puerta china. Para ese proceso el gobierno dominicano contó con la participación protagónica de su comunidad china. Personalidades como Rosa Ng encabezaron el proyecto cuya gestión consolidó la identidad que de facto tenía esa partecita de Santo Domingo, donde la comunidad china se asentó y fundó asociaciones y comercios mucho tiempo atrás. ${ }^{18}$

El Barrio Chino de Belgrano en Buenos Aires tiene su centro en Arribeños en una concentración de cuatro manzanas y fue fundado por los inmigrantes taiwaneses. Es resultado de dos períodos bien diferenciados de inmigración china hacia la Argentina, en las décadas del 80 y 90 del XX, procedentes de Taiwán y de la Rep. Popular China respectivamente (Bogado, 2011). Actualmente se cuentan unos 200.000 chinos dispersos en varias ciudades del país, de los que el $80 \%$ vive en Buenos Aires, realzando la notoriedad del Chinatown porteño, que por sus diversas actividades y manifestaciones culturales chinas se transformó en punto turístico intercultural de la ciudad (Pappier, 2011). ${ }^{19}$

\section{Nuevas propuestas de "barrios chinos" como atractivos comerciales y turísticos}

Como se ha adelantado, a partir de la década de 1990 en algunas ciudades de países latinoamericanos se han emprendido proyectos de reanimación, creación o construcción de "barrios chinos". Más bien son zonas (calles, bulevares o manzanas) comerciales caracterizadas, que concentran establecimientos dedicados a la oferta de productos y servicios típicos chinos, decorados y ambientados (música, personas chinas, tanto trabajadores como clientes) a la usanza china tradicional.

Ejemplo de ello son los procesos de restauración en los viejos barrios chinos de Lima, La Habana, así como en ciudad México y Santo Domingo. Sin embargo, en algunos casos han presentado incoherencias en el tratamiento conceptual y de proyecto, así como en la ejecución del mismo, denotando las contradicciones de intereses de la voluntad gubernamental local y la comunidad china y otras fuerzas locales. Alguno se ha caído, como el Proyecto de Reanimación Integral del Barrio Chino de La Habana, que perdió el protagonismo de la comunidad de origen chino, diluyéndose en el sistema de la Oficina del Historiador de la ciudad de La Habana, que obedece a otros conceptos de revitalización socio-urbana. En la ciudad de México, la falta de cohesión entre los distintos grupos de la comunidad no ha permitido mayores resultados.

Otro ha sido el caso de San José en Costa Rica, donde los chinos no contaban con su barrio (Rodríguez, 2013), a pesar de estar en el país desde 1855, por las necesidades de mano de obra en trabajos domésticos y agrícolas (Chen, 2013).

18 La autora visitó la zona y realizó intercambios con miembros de la comunidad china dominicana en sus establecimientos comerciales y asociaciones años atrás en abril de1999

19 La autora realizó dos visitas de observación al Barrio Chino de Belgrano (noviembre 2011 y septiembre 2015) 
Justamente en el 2007 las relaciones bilaterales China-Costa Rica dan un salto con la apertura de las embajadas respectivas, dejando atrás la era Taiwanesa. A la sazón, San José fue estremecida con el proyecto que lanzara la alcaldía en el 2008 de establecer un barrio chino cuyo eje central sería una calle peatonal de 550 metros de largo en el Paseo de los Estudiantes, frente a la zona La Catedral de La Soledad, sitio de la ciudad donde ya existía una vida comercial y cultural y poseía una historia relevante para sus habitantes. Su inauguración tuvo lugar en diciembre del 2012 con la ceremonia ante el Arco de Entrada, resultado de la colaboración entre los dos países -China y Costa Rica-. Existía la esperanza del auge comercial y turístico que le acompañaría, lo cual fue unas de la razones de ese empeño. Sin embargo, a poco más de un año del momento inaugural la situación ya parecía cuesta abajo, visualizándose un proceso de prematura des-comercialización del lugar, a pesar de los esfuerzos como el de elaborar el arroz frito más grande del mundo para la Fiesta de Año Nuevo Chino, en febrero del 2013 (El comercio, 2013). Siguiendo las noticias de la prensa digital, mucha certeza lógica tienen las reflexiones publicadas a las que tuvimos acceso: "Ni tan barrio ni tan chino" (Murillo, 2013). "Barrio chino sin chinos. Los barrios, las calles y las plazas, o tienen historia, o no son nada" (Obregón Valverde, 2012). ${ }^{20}$

\section{Presencia china en otras ciudades latinoamericanas}

En otras importantes ciudades, capitales de países latinoamericanos no se consideran barrios chinos como tales, pero se observa la concentración de los chinos, sus viviendas y sobre todo sus negocios en calles, barrios y zonas céntricas de las ciudades, regularmente en las partes antiguas de las ciudades conocidas en inglés como downtown. Son los casos de Santiago de Chile, donde se concentran en el barrio de Unión Latinoamericana-Estación Central21; en Sao Pablo, Brasil, donde fueron asentando sus viviendas y comercios en la calle Libertad y después han ido poco a poco desplazándose hacia la 25 de Marzo. A pesar de que los chinos son el segundo más numeroso grupo étnico de Brasil -el primero son los japonesesnunca completaron un barrio chino a la usanza tradicional (Carruitero, 2011). En Caracas también existe una alta concentración de chinos, a pesar de no tener un barrio chino y que la comunidad china está presente por todo el país.

20 La autora ha realizado visitas de observación a la zona durante la etapa de construcción en el 2012 y más recientemente en el 2019 pudo visualizar el estado de la cuestión.

21 La autora ha realizado visitas de observación al lugar e intercambiado con estudiosos de la comunidad china de la zona como es el antropólogo Jorge Moraga Reyes, de la Universidad Central de Chile. 


\section{Consideraciones no finales}

Los barrios chinos no son China. Son resultado de una manera única de interrelaciones sociales de todo tipo en condiciones específicas. Para la sociedad receptora, los elementos nuevos que traen los miembros de la comunidad inmigrante son recibidos y apropiados selectiva, pero inevitablemente, reflejados en una suerte de expresiones exóticas primero y más tarde trasformadas y asimiladas como propias en un enjambre mixturado de elementos de todas las raíces etno-culturales locales. El grupo diaspórico que se asienta en la sociedad anfitriona-receptora está obligado a un proceso de readaptación, de reformulación, de reconstrucción creativa de sus recursos culturales de todo tipo -los propiamente sociales y culturales, los de reproducción económico-productiva-.

En definitiva, las comunidades chinas y sus asentamientos tienen en los barrios chinos formas acabadas que sintetizan historia, representaciones e imaginarios de las comunidades chinas en la diáspora. Han sido los modos pioneros en que "lo chino" se presenta en Occidente. Son los antecedentes de la actual omnipresencia china en esta era globalizada. Puede constituir -de hecho lo está siendo- una de las maneras de conexión, utilizable -prevista o espontánea- para el crecimiento de las relaciones bilaterales entre los países y sus gobiernos. El texto más arriba trata de ejemplos tales como las renovaciones de los barrios o zonas chinas históricas en La Habana, México, Lima, Santo Domingo, o el nuevo barrio de San José. Pero, muy particularmente, estas comunidades y sus asentamientos caracterizados han servido al acercamiento entre los habitantes locales con los inmigrantes y sus culturas. Para los habitantes de aquellos lugares donde los chinos están presentes en viejas comunidades, cualquier expresión de presencia china no les es extraña, ni tan impactante, como en otros casos en que no existieron estos antecedentes ni sus precursores.

Los barrios chinos son construcciones de la diáspora china. Y como Monica Cinco deja magistralmente claro "las diásporas son formaciones sociales y culturales surgidas de procesos locales de inclusión y exclusión, (entendiendo como local el contexto inmediato en el marco de lo nacional), en ámbitos transnacionales, (entendiendo transnacional como procesos anclados en y/o más allá uno o varios estados nación), y de escala global". Sus historias "se originaron en contextos locales -históricamente pre nacionales- con políticas de la pertenencia y la diferencia bien establecidas, las cuáles dieron nacimiento y siguen promoviendo las vidas diaspóricas...". Son localidades que "se construyen primariamente de forma relacional y contextual” (Cinco, 2017, p.47-48) muy complejamente. En la conformación de las identidades de las comunidades chinas en la diáspora participan intereses y mecanismos hegemónicos de los estados nación involucrados, dígase China y el país receptor, este último marca significativamente la diferencia entre las distintas comunidades latinoamericanas.

En nuestra región y con el tiempo, el aspecto latino y caribeño de estos barrios étnicos -en particular el habanero, sujeto de varios estudios de esta autorase caracteriza por el alto mestizaje biológico y cultural en la composición de la comunidad, lo que los diferencia de los Chinatowns en Norteamérica, e incluso los de Europa y Asia. 
Han tenido en común procesos de revitalización de las tradiciones chinas, siendo la reanimación o la creación de zonas comerciales chinas con fines turísticos y comerciales una de las manifestaciones de ese proceso que se inicia en la última parte del siglo XX y aún continúa. Las autoridades gubernamentales se han servido de estos eventos para enarbolar los valores patrimoniales en los escenarios políticos, como instrumentos de la política bilateral. Pero siempre no ha existido complementación en las esferas social y cultural, y muchas veces no se corresponden con los intereses y las aspiraciones de las comunidades y de las poblaciones locales chinas y no chinas del país anfitrión. No ayuda tratar de conformar, contra natura sociocultural, procesos en los que necesariamente tiene que intervenir protagónicamente la comunidad portadora originaria de los valores que se pretenden patrimonializar y sin cuya participación comprometida es imposible lograr autenticidad y mucho menos éxito como proyecto económico, social y cultural. En estos procesos intervienen importantísimos elementos como la sedimentación histórica de los hechos y procesos socioculturales y el componente étnico, variable clave. 


\section{Referencias bibliográficas}

Alba, X. (2009). Frontera de mercancías, El Chinatown de Mexicali, fachada de un Barrio Transnacional (Tesis de Licenciatura). Universidad Autónoma Metropolitana de México.

Bogado Bordazar, L. (2011, 10 y 11 de noviembre). Migración china en los países del MERCOSUR. Principales flujos y proyecciones. Ponencia en Primer Congreso Latinoamericano de Estudios Chinos. Universidad Nacional de La Plata.

Carruitero, M. (2011, 10 y 11 de noviembre). Representaciones sociales e identidad de la mujer china en Argentina. I Congreso Latinoamericano de Estudios Chinos. Universidad Nacional de La Plata.

Carpentier, A. (2002). Descubrimiento de la Habana. Lo que fue el teatro Chino. En Crónicas del Regreso (pp. 25-27). Letras Cubanas.

Checa-Artasu, M. (2013). Las primeras migraciones chinas en el Caribe. Un análisis desde la geografía. En L. Arsovska (coord.), América Latina y El Caribe - China. Historia, Cultura y Aprendizaje del Chino (pp. 111-127). Unión de Universidades de América Latina y el Caribe.

Chen Mok, S. (2013). Una caracterización del comerciante chino en la Ciudad de Puntarenas en la actualidad. Los resultados de un trabajo de campo. En S. Chen Mok, J. Barttels Villanueva y R. Martínez Esquivel (edits.). Estudios sobre China desde Latinoamérica. Geopolítica, Religión e Inmigración. Universidad de Costa Rica - Sede del Pacífico.

Chufat Latour, A. (1927). Apunte Histórico de los Chinos en Cuba. Molina y Cía. Habana.

Cinco Basurto, M. (2014). Espacios de la sinidad en la Ciudad de México. UNAM.

Cinco Basurto, M. (2017). A mí no me pueden volver a sacar. Etnografía práctica desde los márgenes de la diáspora china mexicana (Tesis de Doctorado). Universidad Autónoma Metropolitana. Unidad Iztapalapa.

Eng, Y. (2003). Culíes Chinos en Cuba: esclavos contratados. Del Caribe, 42, 82-89.

Eng, Y. (2007). Ethnicity and Autorecovery: Havana’s Chinatown. En I. López-Calvo, Alternative Orientalism in Latin America and Beyond (pp. 134-143). Newcastle, UK: Cambridge Scholars Publishing (2011). Asiáticos en el Caribe: encuentros y desencuentros. Introducción a un estudio comparativo. En M. Martínez, Milagros y J. Laguardia (Selección y compilación), El Caribe en el siglo XXI. Coyunturas, perspectivas y desafíos (pp. 205-232). Ed. Ciencias Sociales.

Eng, Y. (2013a). La vigencia de las comunidades chinas en las nuevas relaciones económicas y políticas bilaterales: el proyecto del Barrio Chino de La Habana en los 90 del siglo XX. En J. Martínez Cortés (coord.), América Latina y El Caribe - China. Relaciones Políticas e Internacionales (pp.509-527). Unión de Universidades de América Latina y el Caribe. 
Eng, Y. (2013b) Proyecto de investigación: el chino latino como identidad en construcción por más de siglo y medio. Estudio de caso del chino-cubano. En L. Arsovska (coord.), América Latina y El Caribe - China. Historia, Cultura y Aprendizaje del Chino (pp.129-148). Unión de Universidades de América Latina y el Caribe.

Eng, Y. (2015). Barrios chinos de América Latina y El Caribe. En L. Arsovska (coord), América Latina y el Caribe y China. Historia, cultura y aprendizaje del chino 2015 (pp. 63-78). Red Académica de América Latina y el Caribe sobre China y Unión de Universidades de América Latina y el Caribe.

Genthe, A. \& Wei Tchen, J. (1984). Genthe's Photographs of San Francisco's Old Chinatown. Dover Publications, Inc.

Gómez Díaz, D. (2013). China y su relación con América Latina. Una aproximación desde el poder blando. En J. Martínez (coord.), América Latina y El Caribe - China. Relaciones Políticas e Internacionales (pp. 47-64). Unión de Universidades de América Latina y el Caribe.

Hearn, A. (2012). Harnessing the Dragon: Overseas Chinese Entrepreneurs in Mexico and Cuba. The China Quarterly, 209, 111-133.

Hearn, A. (2016). Diaspora and Trust. Cuba, Mexico, and the rise of China. Duke University Press.

Hu-DeHart, E. (1982). Racism and Anti-Chinese. Persecution in Sonora, Mexico, 1876-1932. AMERASIA, 9(2), 1-28.

Hu-DeHart, E. (2009). Indispensable Enemy or Convenient Scapegoat? A Critical Examination of Sinophobia in Latin America and the Caribbean, 1870s to 1930s. Journal of Chinese Overseas, 5, 55-90.

Hu-De Hart, E. (2012). Chinatowns and Borderlands: Inter-Asian encounters in the diaspora. Modern Asian Studies, 46 (2), 425-451

Lai, David \& Madoff, P. (1997). Building and Rebuilding Harmony. The Gateway to Victoria's Chinatown. Canadian Western Geographical Series, 32. University of Victoria.

López, K. (2004). One Brings Another: The Formation of Early-Twentieth-Century Chinese Migrant Communities in Cuba. En A. Wilson. (edit.), The Chinese in the Caribbean (pp. 93-128). Markus Weiner Publishers.

López, K. (2010, 6-9 de Octubre). Latin American Chinatowns as a Response to the Financial Crisis. Ponencia presentada en Congreso LASA (Latin American Studies Association).

López, K. (2013). Chinese Cubans. A Transnational History. The University of North Carolina Press. 
López-Calvo, I. (ed.). (2007). Alternative Orientalism in Latin América and Beyond. Cambridge Scholars Publishing.

Obregón Valverde, E. (2012). "Barrio Chino sin chinos", La Nación, 14 de marzo de 2012.

Ortiz, F. (1970) [1940]. El Contrapunteo Cubano del Tabaco y el Azúcar. Biblioteca Nacional José Martí.

Padura, L. (2002). El viaje más largo. Editorial Plaza Mayor.

Pan, L. (1990). Sons of the Yellow Emperor. A history of the Chinese Diaspora. Little, Brown and Company.

Pan, L. (ed.) (1999). The Encyclopedia of the Chinese Overseas. Harvard University Press.

Pappier, A. 2011. El barrio chino de Buenos Aires y su transformación en punto turístico intercultural de la ciudad, I Congreso Latinoamericano de Estudios Chinos, Universidad Nacional de La Plata.

Rodríguez Pastor, H. (2001). Hijos del Celeste Imperio en el Perú (1850-1900). Migración, agricultura, mentalidad y explotación. Sur, Casa de Estudios del Socialismo.

Rodríguez Pastor, H. (2004). La Calle Capón, el callejón de Otaiza y el Barrio Chino. En A. Panfichi y F. Portocarrero (edits.), Mundos Interiores Lima 1850-1950 (pp. 45-61). Universidad del Pacífico.

Rodríguez Solano, P. (2013). Migración, sociabilidad y estado: la comunidad china y su inserción a Costa Rica (1870-1930). En S. Chen Mok, J. Barttels y R. Martínez Esquivel (edits.), Estudios sobre China desde Latinoamérica. Geopolítica, Religión e Inmigración (pp. 218-234). Universidad de Costa Rica - Sede del Pacífico.

-Tam, J. (2006). Huellas Chinas en Panamá. 150 años de presencia. Únicos Impresores.

Murillo, Á. (2013). Ni tan barrio ni tan chino. http://www.nacion.com/nacional/ politica/barrio-chino_0_1345065516.html

Chinatowns in Latin America. (2013). Wikipedia, the free encyclopedia. http://en.wikipedia.org/wiki/Chinatowns_in_Latin_America

Cocinan arroz frito más grande del mundo 2013 (2013, 12 de febrero). Diario El Comercio. http://elcomercio.pe/gastronomia/1536153/ noticia-costa-rica-cocinan-arroz-frito-mas-grande-mundo-ano-nuevo-chino

Aquí se inventó el arroz chaufa limeño. Barrio Chino de Lima, Calle Capón. (2014). Guía Turística de Lima. Lima http://www.limaperu.tv/centro-historico/ barrio-chino-calle-capon/ 